\title{
Evaluation of Soil Swelling and Liquefaction Potential Using a GIS Software: a Case Study of Tabriz, Iran
}

\author{
Reza Saberi ${ }^{1 *}$, Majid Alinejad², Hadi Nasiri³, \\ Kamran Sepanloo' \\ ${ }^{1}$ Nuclear Science and Technology Research Institute (NSTRI), P.O. \\ Box 113658486, Tehran, Iran \\ ${ }^{2}$ Engineering Research Institute of Natural Hazard, \\ Shakhespajouh, Isfahan, Iran \\ ${ }^{3}$ Urmia University, Urmia, Iran \\ Study Area: Tabriz, Iran \\ Coordinates: $38^{\circ} \mathrm{O} 4^{\prime} \mathrm{N} ; 46^{\circ} 18^{\prime} \mathrm{E}$
}

Key words: Earthquake, Land hazard, Arc GIS software, Soil improvement, Plastic index, Zoning map.

\section{Introduction:}

Liquefaction is a phenomenon where a saturated soil which is under severe stresses, completely loses its strength and stiff ness and behaves like a liquid. This stress could be an outcome of earthquakes or sudden changes in soil conditions. If the water pore pressure would be high enough to exceed the ability of soil grains to withstand the load, then the soil grains would get separated by water and soil status become like liquated sand. This phenomenon has been seen more in saturated soils, loose (low-density or non-compacted soils) and sandy soil. Loose sand tends to be compacted under these loads, but compacted sand tends to increase in volume under such conditions (Bengt, 1993). If the soil would be saturated with water; conditions such as groundwater or soil below the sea level, then the water fills the space between the solid particles (pore space). If a pressure would be applied to the soil, the water pressure will increase in these spaces. In contrast, water tends to get out of the pore spaces and flow to where the pressure would be less (usually water moves up the ground or upward). However, if this pressure comes fast and big enough or repeatedly in large numbers (like earthquake

\section{Abstract}

Worldwide research on inflation and soil liquefaction is in nowadays a hot cake. Critical issues on soil liquefaction can cause irreparable effects to surface and undersurface installation the results which could be easily realized through the accidents like, derailment of rail, distortion in the roads, bend building, damage to the pipelines and an even close cross-section of the tunnel and reversal structures. Thus maintaining some specific patterns is always felt necessary to identify such points to avoid these destructive phenomena, and the structures would remain safe in coming future from vulnerabilities of hazards. We aimed this study to forward some guidance to identify and modif ies regions having critical issues relating to the high liquefaction. From 50 excavated bores, total standard influence numbers and the Atterberg limits at different depth have been calculated. Further, by using of Arc GIS application, geostatistics analysis tool and by using of interpolation Kriging method, zoning maps of liquefaction and critical situation have been estimated. The obtained results hope to be useful in future plans to decrease the relevant accidents.

condition or a pressure from the hurricane) so that water cannot find enough time to exit until the next round (next cycle) then by the result of this pressure, grains from the soil flows out. Indeed the contact between soil grains is the only way to transmit the weight of the building and its layers to the lower layers of soil or bedrock at a higher depth.

However, when soil loses its structure and contacts between solids then the whole profile of soil would not show any resistance (Abdullah et al., 1999). Some expansive soils are that soils which may encounter a significant increase in volume as a result of the moisture content changes. The best description of this phenomenon is the physical and chemical reactions in between the soil and its environment and the amount of swelling depends on the severity of the reactions in between the physical and chemical forces of attraction and repulsion (Sridharan \& Gurtug, 2004). Changes in moisture content due to seasonal changes in weather or some other artificial factors, alter the mechanical properties of the soils, especially on the clay soils. The degree of swelling depends on the activity of the minerals 


\section{TECHNOSCIENCE ARTICLE}

of clay soil. Pre-consolidated clays, Quaternary and Tertiary sedimentary layers, basalt and weathered shales, are the known components of the expansive soils. Expansive soil can be found in most parts of the world such as Argentina, Spain, Australia, America, Iran, Turkey, Palestine, Canada, and India (Kramer, 1996). In the Iranian provinces of Khuzestan, Fars, Kerman, Yazd, and parts of Khorasan, this type of clay exists more than any other place of the world (Seed et al., 1962).

By keeping in mind that Iran is located in the earthquake-prone belt of Alpine - Himalayan, it can be said that earthquakes are the most destructive natural disasters in this country. The destructive effects of natural disasters such as earthquakes, floods, and slope movements such as avalanches, rock fall, and landslide in all regions of the world have catastrophic results in the destruction of human settlements pose. The destructive effects of natural phenomena in the developing countries are more vulnerable compared to developed nations. In the case of soil swelling, it can be said that change in soil moisture content can change the volume of the soil, especially those in arid and semi-arid climatic zones (Williams \& Donaldson, 1980). Change of soil volume can cause damage to the road pavement, rails, and building. For example, damage caused by soil swelling in America is about seven billion dollars annually which is nearly the double of the damages caused by floods, storms, and earthquakes (Kramer, 1996).

For soil swelling and liquefaction assessment, a detailed report of subsurface explorations and geotechnical field with laboratory tests are required in addition to the earlier reports. The liquefaction potential estimation method comprises the following steps:

- Estimation of soil resistance against liquefaction.

- Estimation of the maximum or equivalent shear stress cycle by the earthquake which is likely to occur in the soil.

- Potential estimation of liquefaction based on information about deposits Resistance against the liquefaction may be calculated based on vitro tests on intact samples such as cyclic triaxial shear tests and field tests such as SPT (standard penetration test) and CPT (dynamic penetration test), which are usually in use today (Youd \& Hoose, 1977).

Excellent restructuring of undisturbed samples and laboratory testing are the most accurate evaluation process for prediction of periodic resistance of sand. However, obtaining samples of sand from the aquifer sediments is an expensive task and could be recommended only for the administrative project. Therefore it is important to make the process easier and economically and also it is better to consider a viable alternative for determining the resistance of sand. During the last three decades a method called "simplified procedure" was
Ambient Science, 2018: Vol. 05(1); 22-27 DOI:10.21276/ambi.2018.05.1.ta02

randomly used to evaluate the potential of soil liquefaction. It was founded by Seed \& Idriss (1971) and also was corrected over the time according to the information about the previous earthquakes (Youd \& Idriss, 2001; BSSC, 2003). In this study, the amount of the maximum ground acceleration was $0.3 \mathrm{~g}(\mathrm{amax}=0.3 \mathrm{~g})$. Based on earthquakes occurred in the region and regulations for the 2800 earthquake code, it was assumed that the magnitude of a probable earthquake is 7.5 Richter. In general, the philosophy of soil liquefaction assessment is presented in five sections (Joyner \& Boore, 1981).

\section{The prescribed formula has been used for:}

- Calculation and correction of standard penetration test number (Fardis et al., 2005)..

- Soil mass cyclic shear stress ratio (CSR) (ASCE, 1922) fllowed by Idriss ( 1999).

- Cyclic shear strength of the soil mass and its correction (CRR) (Burrough, 1986).

- Factor of safety (Fs) (BSSC, 2004).

- Liquefaction index (PL) (Joyner \& Boore, 1981).

There are several ways to evaluate the potential of soil swelling, but the "Plastic Index" method to evaluate the potential for swelling gives the better results (Sorochan \& Ryabova, 1988). The relationship between soil plasticity index and the index of swelling is mentioned below:

Table-1: Relation between swelling potential and plasticity index

\begin{tabular}{ll}
\hline Plasticity index & Swelling Potential \\
\hline o to 15 & low \\
15 to 30 & medium \\
30 to 45 & high \\
More than 45 & Very high \\
\hline
\end{tabular}

Earthquake vibrations or dynamic loads cause liquefaction in loose saturated granular soils the most important reason for this phenomenon is the occurrence of delay in drainage procedure and sudden increase in water pore pressure. The major common methods to deal with such situation are as follow (Bengt, 1993):

- Excavation and replacement of soils susceptible to liquefaction.

- Drainage.

- Changing the nature of the soil by injection.

- Densification of the available soil.

One method to deal with soil swelling is soil stabilization with lime which will improve soil geotechnical properties for a specific purpose. The use of lime improves the strength properties. Reaction with lime for soil stabilization achieves high strength more than the reaction of the cement. Use of lime for swelling soil stabilization occurs for three reasons:

1) Strong calcium ions will be exchanged with sodium ions in limestone or clay.

2) Using lime soil, the texture becomes scattered; 
3) Swelling soil would be replaced with lime.

Percentage of lime should be determined by testing, but it is about 2 to 8 percent. It is worth on useing the lime, liquid limit and plasticity index with decrease and finally plastic characteristics will be improved (Oates, 2008).

\section{Methodology:}

Study area: Tabriz is one of the major cities in Iran and the capital of East Azerbaijan province. The city is a largest economic center in the northwestern area of Iran and is known as administrative, communication, commercial, political, and cultural center in the northwest of Iran. Tabriz experiences devastating earthquakes and thus there is always a probability for another big earthquake in this region which is the purpose we have to evaluate the liquefaction and also soil swelling potential in the area of this city. For this purpose, SPT test data and Atterberg Limit experiments which were conducted by Padir company for 50 drilled holes were used. The following image (Fig.-1) shows the exact location of each borehole. Table -3, shows the initial data for each borehole.

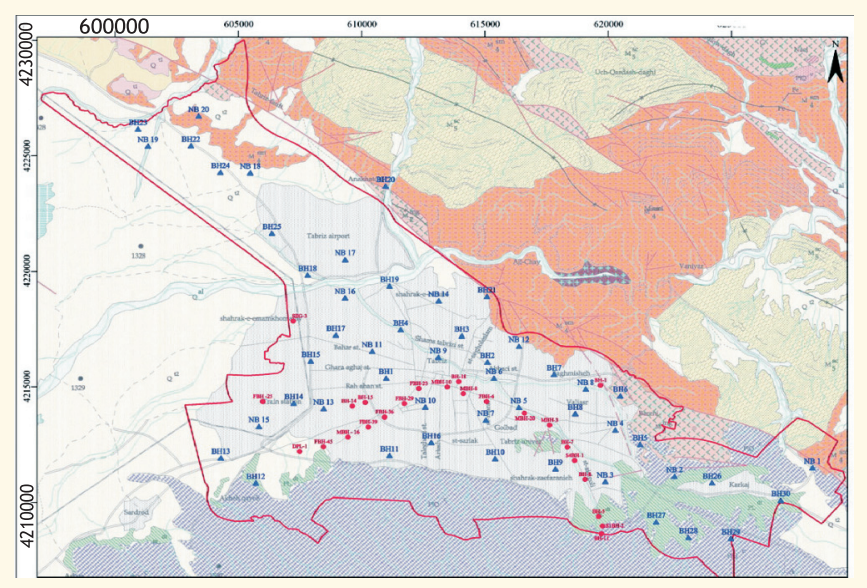

Figure 1: Location of bore holes around the city

(The map is prepared by Padir. Company).

Following the figure and table, the average number of SPT (NSPT) in three depth ranges of o to 7 meters, 7 to 14 meters and 14 to 20 meters was calculated. The reason for choosing of the aforementioned values is that the phenomenon of liquefaction is probably only up to a maximum depth of 20 meters. In addition, the mean values of plastic and liquid limits were calculated in depth range of $o$ to 10. According to a previous sentence, the reason for choosing this value was this fact that soil swelling is only probably up to a depth of 10 meters.

In order to evaluate the potential of soil liquefaction and swelling, standard penetration test data, liquid limit and the plastic limit is mandatory. However, using the available empirical relationships, swelling and liquefaction potential were calculated and then the same was compared with the standard values. In this study, the potential of liquefaction and soil swelling was calculated through liquefaction index (PL) and swelling index (S).
The calculated values of liquefaction and soil swelling potential can be seen in Table-4. In order to have a better understanding of the situation in the drilled boreholes, the calculated values of swelling and the liquefaction potential have been compared with standard values (Table $1 \& 2)$.

For Zoning maps of liquefaction and soil swelling an introduction to the ArcGIS software and Geostatistical analyzer tool was employed. ArcGIS is comprehensive software for design and management of solutions, this software is based on knowledge of geography. This software able to perform in-depth analysis, to gain a greater understanding of their data and make more informed decisions at high levels. ArcGIS software makes it simple to conduct a geographical analysis, without the need for GIS expertise. The most important aspects of this version (10.2) is that the users of ArcGIS can be a source of GIS, maps, pictures, location information, and tools, as a web service access. Sample points provide height, depth or have pollution levels. Geostatistical modeling of spatial analysis can also be used in various applications such as Spatial Information System. One advantage of the tools and methods is that the sample points are mostly fitted to the model surface. In this study, we used ArcGIS software and the geostatistical analyzer to produce zoning map of liquefaction and soil swelling potential.(Hengl et al., 2004; Johnson \& Wichern, 1992).

\section{Results:}

In the previous part of the research, quantities needed for liquefaction and soil swelling assessment were provided (Kramer, 1996). Then, after a brief introduction of the ArcGIS software and its capabilities in the preparation of zoning maps, now, it is time to produce the zoning maps. Kriging interpolation method used for this purpose. At first step of zoning process, all tables and maps has been introduced by Arc Catalog module. Then in Arc MAP module maps and tables have been added. Using the Geostatistical Analyzer tool and choosing Kriging interpolation method the liquefaction and soil swelling zoning maps has been produced. The left side of each map is also given instructions that can be compared with standard values (Table $1 \& 2$ ). Zoning maps are shown in Figures 2 to 5 .

Table-2: Classification of liquefaction potential

\footnotetext{
PL Liquefaction Hazard and Measures needed

o Liquefaction risk is very low and generally do not feel the need to research more accurate

o to 5 Liquefaction risk is low and needs more detailed studies.

5 to 15 Liquefaction hazard is moderate, recommended research and corrective methods are necessary.

$>15$ High liquefaction hazard and it is important to do more detailed studies and appropriate methods should be adopted.
} 
TECHNOSCIENCE ARTICLE
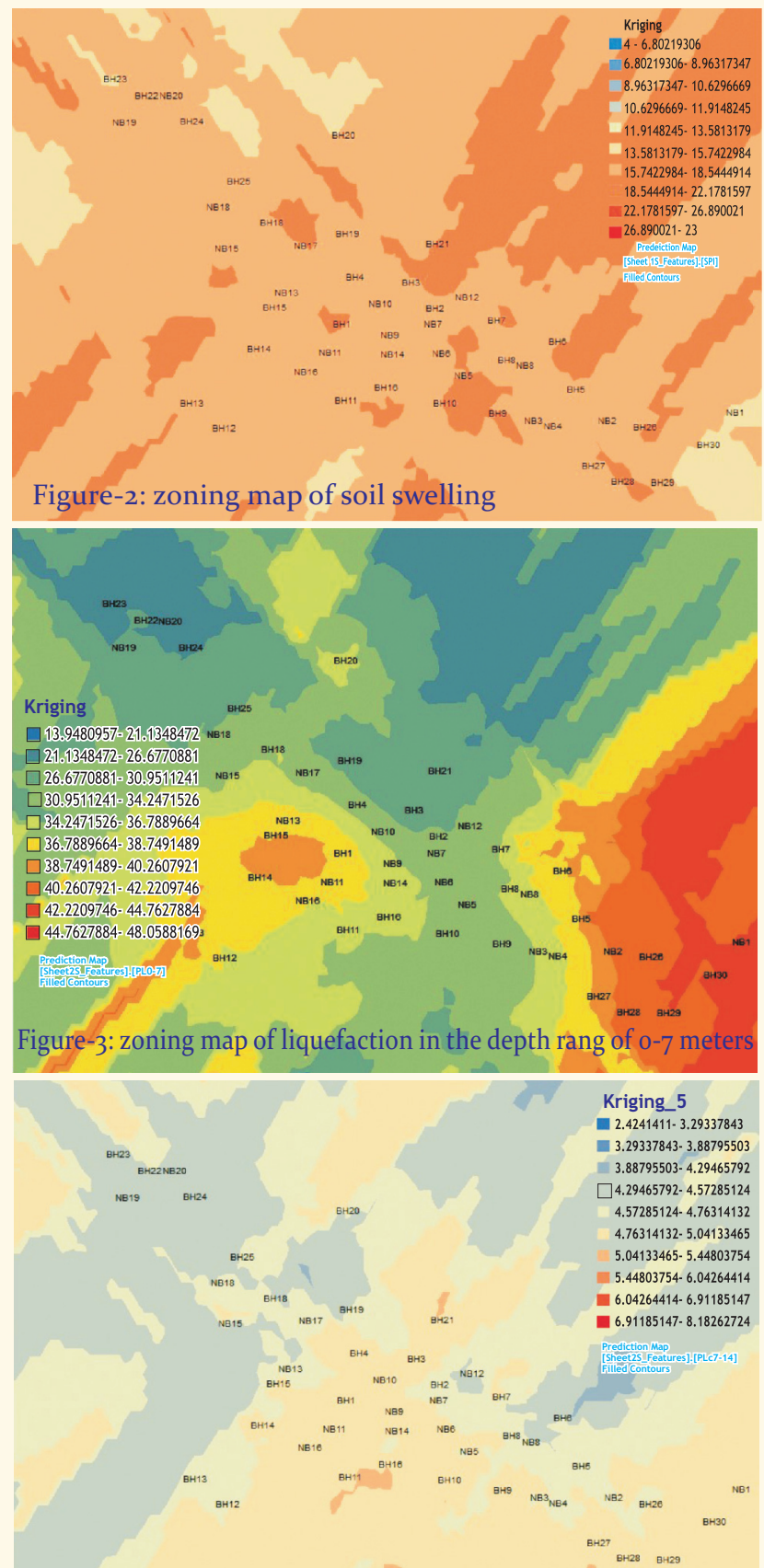

Figure-4: zoning map of liquefaction in the depth rang of $7-14$ meters

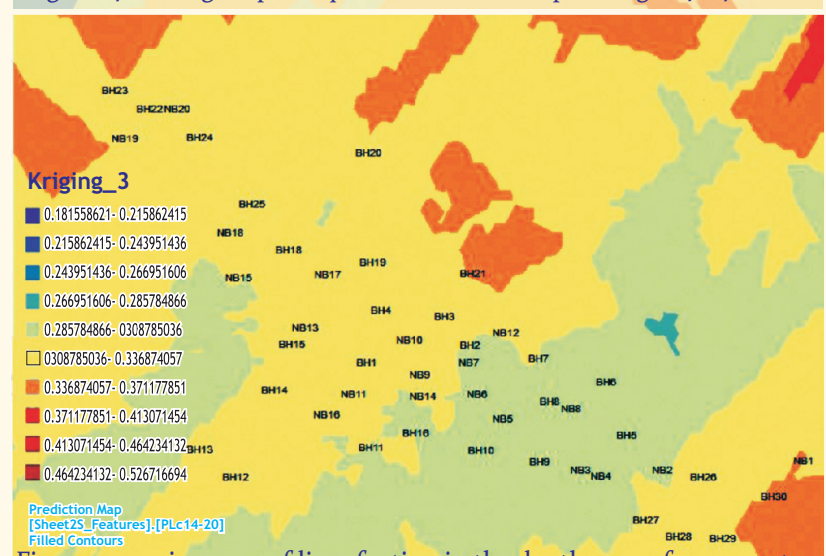

Figure-5: zoning map of liquefaction in the depth rang of $14-20$ meters
Table-3: Characteristics of all boreholes

Bore Latitude Longitude NSPT NSPT NSPT PL LL

Hole $\quad(0-7) \quad(7-14) \quad(14-20)$

\begin{tabular}{llllllll}
\hline BH1 & 610995 & 4215346 & 12 & 20 & 22 & 43 & 31
\end{tabular}

$\begin{array}{llllllll}\mathrm{BH} 2 & 615103 & 4216043 & 14 & 35 & 80 & 41 & 17\end{array}$

$\begin{array}{llllllll}\mathrm{BH}_{3} & 614066 & 4217176 & 106 & 110 & 100 & 39 & 18\end{array}$

$\begin{array}{llllllll}\mathrm{BH}_{4} & 611586 & 4217437 & 18 & 28 & 65 & 45 & 22\end{array}$

$\begin{array}{llllllll}\mathrm{BH}_{5} & 621296 & 4212480 & 31 & 70 & 100 & 63 & 33\end{array}$

$\begin{array}{llllllll}\text { BH6 } & 620495 & 4214579 & 14 & 15 & 45 & 49 & 27\end{array}$

$\begin{array}{llllllll}\mathrm{BH}_{7} & 617807 & 4215510 & 55 & 140 & 100 & 69 & 37\end{array}$

$\begin{array}{llllllll}\text { BH8 } & 618664 & 4213798 & 40 & 50 & 75 & 26 & 13\end{array}$

$\begin{array}{llllllll}\mathrm{BH} 9 & 617860 & 4211419 & 30 & 75 & 90 & 57 & 35\end{array}$

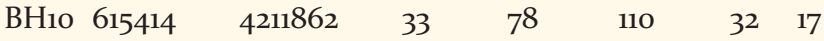

$\begin{array}{llllllll}\text { BH11 } & 611134 & 4211996 & 120 & 79 & 78 & 41 & 17\end{array}$

$\begin{array}{llllllll}\mathrm{BH} 12 & 605708 & 4210801 & 38 & 59 & 100 & 27 & 17\end{array}$

$\begin{array}{llllllll}\mathrm{BH}_{13} & 604292 & 4211896 & 18 & 28 & 30 & 34 & 14\end{array}$

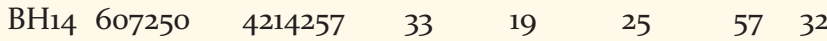

$\begin{array}{llllllll}\mathrm{BH}_{15} & 607944 & 4216088 & 12 & 22 & 28 & 52 & 19\end{array}$

$\begin{array}{llllllll}\mathrm{BH} 16 & 612830 & 4212566 & 33 & 40 & 45 & 47 & 29\end{array}$

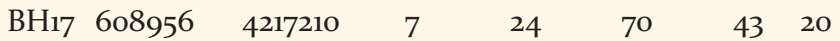

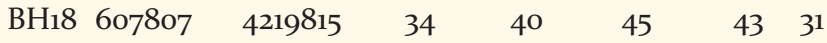

$\begin{array}{llllllll}\text { BH19 } & 611133 & 4219337 & 30 & 47 & 84 & 63 & 34\end{array}$

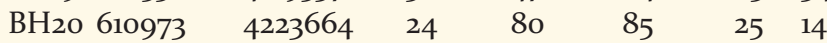

$\begin{array}{llllllll}\mathrm{BH}_{21} & 615087 & 4218880 & 30 & 75 & 90 & 42 & 25\end{array}$

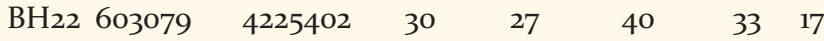

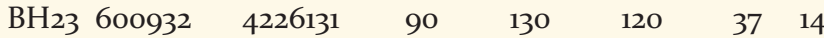

$\begin{array}{lllllll}\mathrm{BH}_{24} 604276 & 4224252 & 130 & 130 & 140 & 39 & 17\end{array}$

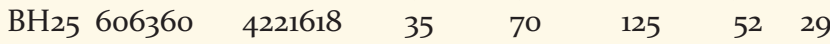

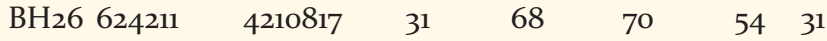

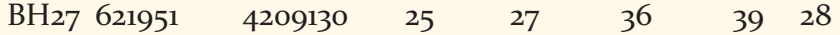

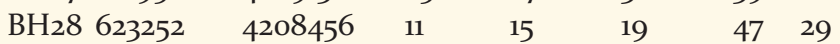

$\begin{array}{llllllll}\mathrm{BH} 29 & 624974 & 4208403 & 21 & 28 & 38 & 43 & 26\end{array}$

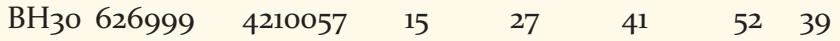

$\begin{array}{llllllll}\text { NB1 } & 628291 & 4211465 & 18 & 18 & 17 & 43 & 29\end{array}$

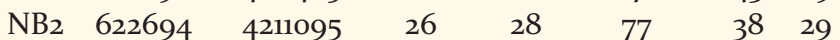

$\begin{array}{llllllll}\mathrm{NB}_{3} & 619885 & 4211095 & 48 & 79 & 75 & 44 & 30\end{array}$

$\begin{array}{llllllll}\mathrm{NB} 4 & 620290 & 4210861 & 61 & 76 & 97 & 62 & 30\end{array}$

$\begin{array}{llllllll}\text { NB5 } & 616378 & 4213110 & 28 & 41 & 77 & 32 & 21\end{array}$

$\begin{array}{llllllll}\text { NB6 } & 615370 & 4214078 & 43 & 42 & 54 & 52 & 29\end{array}$

$\begin{array}{llllllll}\text { NB7 } & 615040 & 4215349 & 30 & 45 & 60 & 51 & 28\end{array}$

$\begin{array}{llllllll}\text { NB8 } & 619090 & 4213534 & 32 & 55 & 82 & 29 & 19\end{array}$

$\begin{array}{llllllll}\text { NB9 } & 613115 & 4214872 & 16 & 34 & 68 & 51 & 31\end{array}$

$\begin{array}{llllllll}\text { NB10 } & 612589 & 4216256 & 24 & 39 & 55 & 30 & 19.5\end{array}$

$\begin{array}{llllllll}\text { NB11 } & 610431 & 4214087 & 17 & 32 & 45 & 24 & 20\end{array}$

$\begin{array}{llllllll}\mathrm{NB} 12 & 616383 & 4216520 & 45 & 76 & 45 & 27 & 20\end{array}$

$\begin{array}{llllllll}\mathrm{NB}_{13} & 608464 & 4216735 & 45 & 76 & 87 & 31 & 20\end{array}$

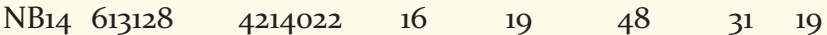

$\begin{array}{llllllll}\mathrm{NB}_{15} & 605836 & 4218700 & 45 & 72 & 81 & 45 & 24\end{array}$

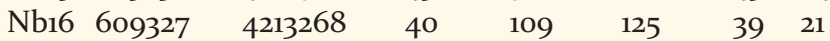

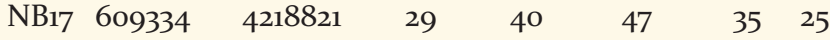

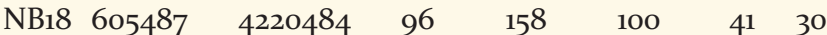

$\begin{array}{llllllll}\text { NB19 } & 601337 & 4224231 & 22 & 40 & 45 & 25 & 19.8\end{array}$

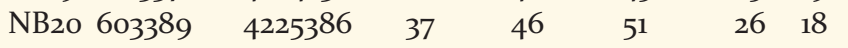

PL: Plastic limit ; LL: Liquid limit; NSPT: average number of standard penetration test 
Table-4: Calculated values of liquefaction and soil swelling potential

\begin{tabular}{|c|c|c|c|c|c|c|c|c|}
\hline $\begin{array}{l}\text { Bore } \\
\text { hole }\end{array}$ & $\begin{array}{l}\text { PL } \\
14^{-20}\end{array}$ & $\begin{array}{l}\text { Cat.- } \\
14-20\end{array}$ & $\begin{array}{l}\text { PL } \\
7^{-14}\end{array}$ & $\begin{array}{l}\text { Cat.- } \\
14\end{array}$ & & $\begin{array}{l}\text { Cat.- } \\
\text { o-7 }\end{array}$ & S.pI & $\begin{array}{l}\mathrm{C} . \\
\mathrm{S} .\end{array}$ \\
\hline $\mathrm{BH}$ & 0.37134 & v L & 5.71327 & $\mathrm{~L}$ & 15.26843 & $\mathrm{H}$ & 12 & \\
\hline $\mathrm{BH}_{2}$ & 0.23605 & v L & 4.55590 & v L & 15.90392 & $\mathrm{H}$ & 24 & \\
\hline $\mathrm{BH}_{3}$ & 0.34158 & v L & 3.92757 & v L & $5 \cdot 79882$ & $\mathrm{~L}$ & 21 & \\
\hline $\mathrm{BH}_{4}$ & 0.33242 & v L & 4.98315 & v L & 14.48844 & M & 23 & \\
\hline $\mathrm{BH}_{5}$ & 0.20381 & v L & $3 \cdot 51010$ & v L & 16.93078 & $\mathrm{H}$ & 30 & \\
\hline BH6 & 0.28990 & v L & 5.67563 & $\mathrm{~L}$ & 15.03013 & $\mathrm{H}$ & 22 & \\
\hline $\mathrm{BH}_{7}$ & 0.28244 & v L & 2.42414 & v L & 11.43767 & M & 32 & \\
\hline $\mathrm{BH} 8$ & 0.30189 & v L & 3.85028 & v L & 12.3142 & $\mathrm{M}$ & 13 & \\
\hline $\mathrm{H}_{9}$ & 0.36739 & v L & 7.62280 & $\mathrm{~L}$ & 2.76747 & v L & 22 & \\
\hline BHıо & 0.19324 & v L & 4.82936 & v L & 13.52568 & $\mathrm{M}$ & 15 & \\
\hline $\mathrm{H} 11$ & 0.41787 & v L & 5.23410 & $\mathrm{~L}$ & 4.36549 & v L & 24 & \\
\hline $3 \mathrm{H}_{12}$ & 0.22536 & v L & $4 \cdot 52737$ & v L & & $\mathrm{M}$ & 10 & \\
\hline $3 \mathrm{H}_{13}$ & 0.36445 & v L & 4.96182 & v L & 14.42643 & M & 20 & \\
\hline $3 \mathrm{H}_{14}$ & 0.38870 & v L & 6.20162 & $\mathrm{~L}$ & 283 & M & 25 & \\
\hline $3 \mathrm{H}_{15}$ & 0.35359 & v L & 5.09509 & $\mathrm{~L}$ & 218 & $\mathrm{H}$ & 33 & \\
\hline $3 \mathrm{H} 16$ & 0.33062 & v L & 4.58678 & v L & $13 \cdot 31238$ & M & 18 & \\
\hline $3 \mathrm{H} 17$ & 0.24959 & v L & 4.84938 & v L & 507 & $\mathrm{H}$ & 23 & \\
\hline $\mathrm{BH} 18$ & 0.33467 & v L & 4.64291 & v L & 289 & $\mathrm{M}$ & 12 & \\
\hline $3 \mathrm{H}_{19}$ & 0.40657 & v L & 6.72304 & $\mathrm{~L}$ & & v L & 29 & \\
\hline $\mathrm{BH}_{2} \mathrm{O}$ & 0.25698 & v L & 3.43706 & v L & 14.48934 & $\mathrm{M}$ & 11 & \\
\hline $3 \mathrm{H}_{21}$ & 0.40153 & v L & $5 \cdot 94978$ & $\mathrm{~L}$ & 3.02464 & v L & 17 & \\
\hline $3 \mathrm{H} 22$ & 0.52671 & v L & 8.18262 & $\mathrm{~L}$ & 2.59344 & v L & 16 & \\
\hline $\mathrm{BH}_{23}$ & 0.27699 & v L & 3.15070 & v L & 28 & $\mathrm{~L}$ & 23 & \\
\hline $\mathrm{BH}_{24}$ & 0.28127 & v L & 3.83651 & v L & & v L & 22 & \\
\hline $3 \mathrm{H}_{25}$ & 0.18155 & v L & 3.93093 & v L & 642 & $\mathrm{M}$ & 23 & \\
\hline $\mathrm{BH}_{2} 6$ & 0.28098 & v L & 3.53498 & v L & 16.65972 & $\mathrm{H}$ & 23 & \\
\hline $3 \mathrm{H} 27$ & 0.35602 & v L & 5.27620 & $\mathrm{~L}$ & 12.80167 & M & 11 & \\
\hline $\mathrm{BH}_{2} 8$ & 0.38583 & v L & 5.48498 & $\mathrm{~L}$ & .61538 & $\mathrm{H}$ & 18 & \\
\hline BH29 & 0.33927 & v L & 5.08014 & $\mathrm{~L}$ & 13.80407 & M & 17 & \\
\hline $\mathrm{BH}_{3} \mathrm{O}$ & 0.31472 & v L & $4 \cdot 94748$ & v L & & $\mathrm{H}$ & 13 & \\
\hline $\mathrm{NB} 1$ & 0.41831 & v L & $5 \cdot 52215$ & $\mathrm{~L}$ & 13.97671 & M & 14 & \\
\hline $\mathrm{NB}_{2}$ & 0.26139 & v L & $5 \cdot 34131$ & $\mathrm{~L}$ & 12.72485 & M & 9 & \\
\hline $\mathrm{NB}_{3}$ & 0.31775 & v L & 3.83543 & v L & 866 & M & 14 & \\
\hline $\mathrm{NB}_{4}$ & 0.26981 & v L & 4.23064 & v L & 61000 & $\mathrm{~L}$ & 32 & M \\
\hline $\mathrm{NB}_{5}$ & 0.27722 & v L & 4.75751 & v L & 12.22783 & M & 11 & \\
\hline NB6 & 0.31500 & v L & 4.82332 & v L & 11.27500 & $\mathrm{M}$ & 23 & M \\
\hline $\mathrm{NB}_{7}$ & 0.37656 & v L & 6.99015 & $\mathrm{~L}$ & 2.85992 & v L & 23 & \\
\hline NB8 & 0.24465 & v L & 4.75385 & v L & 14.03129 & $\mathrm{M}$ & 10 & \\
\hline NB9 & 0.28579 & v L & 4.63663 & v L & 15.25562 & $\mathrm{H}$ & 20 & $\mathrm{~L}$ \\
\hline NB1o & 0.28442 & v L & 4.64228 & v L & 13.57319 & M & 10.5 & $\mathrm{~L}$ \\
\hline NB11 & 0.30788 & v L & 4.75596 & v L & 14.90337 & M & 4 & \\
\hline $\mathrm{NB} 12$ & 0.37734 & v L & 3.83975 & v L & 11.45414 & M & 7 & \\
\hline $\mathrm{NB}_{13}$ & 0.27417 & v L & $3 \cdot 90187$ & v L & 11.63943 & M & 11 & \\
\hline $\mathrm{NB}_{4} 4$ & 0.28624 & v L & 5.47857 & $\mathrm{~L}$ & 14.72082 & M & 12 & $\mathrm{~L}$ \\
\hline $\mathrm{NB}_{15}$ & 0.28892 & v L & 4.03347 & v L & 11.52291 & M & 21 & $\mathrm{~L}$ \\
\hline NB16 & 0.19993 & v L & 2.91823 & v L & 13.27482 & M & 18 & L \\
\hline $\mathrm{NB} 17$ & 0.34768 & v L & 4.94564 & v L & 10.99909 & M & 10 & \\
\hline NB18 & 0.35526 & v L & 2.54721 & v L & 7.21217 & $\mathrm{~L}$ & 11 & \\
\hline NB19 & 0.32393 & v L & 4.49393 & v L & 14.00011 & M & 5.2 & $\mathrm{~L}$ \\
\hline $\mathrm{NB} 2 \mathrm{O}$ & 0.32334 & v L & $4 \cdot 37789$ & v L & 12.42742 & M & 8 & $\mathrm{~L}$ \\
\hline
\end{tabular}

Cat.- Category; PL: Plastic limit; LL: Liquid limit; SPI: Swelling plasticity index; vL- very Low; L- Low; M-Medium; H-High

\section{Discussion:}

The soil type in the study area is made of fine sand and in some parts, clay, and silt. The major geological formation in this area is of the Qom formation. Due to the high level of water and fine sand in this area, the probability of liquefaction always remains high. The soil density is classified as medium density class, that's why liquefaction is expected to occur less in deep parts.

In general, in the East and Southeast parts of the city, as well as a small area in the center of the study area, there is a moderate to high risk of liquefaction. Whereas in other areas, the possibility of occurrence is low. This is due to the lower density of soil in these areas and also high levels of underground water (Fig.-5).

Liquefaction is predicted to occur in the depth range of o-7 meters. In the case of swelling, it can be said that, within the north and north-eastern region, especially due to the presence of a certain type of red clay and silt, soil swelling is prone phenomena. But the probability of its occurrence was low or medium (Fig.-4). The study area in this research has a signif icant population and also it is one of the important political and commercial cities of Iran. Thus a periodic detailed study is always necessary.

\section{Acknowledgements:}

The authors are thankful to the officilas of Padir company to provide their data and Maps for this study.

\section{References:}

Abdullah, W.S., Alshibli, K.A. \& Al-Zou'bi, M.S. (1999): Influence of pore water chemistry on the swelling behavior of compacted clays. Appl. Clay Sci., 15(5): 447-462.

ASCE (American Society of Civil Engineers) (1922). Transactions of the American Society of Civil Engineers. Pub. by: American Society of Civil Engineers.

Bengt, B.B. (1993): Ground improvement. Pub. by: John willey and Sons Publishing Company.

BSSC (Building Seismic Safety Council of the National Institute of Building Sciences), (2004): NEHRP Recommended Provisions for Seismic Regulations for New Buildings and Other Structures (FEMA 450), 2003 Edition. Prepared by the BSSC for the Federal Emergency Management Agency, Washington, D.C.

Burrough, P.A. (1986): Principles of Geographical Information Systems for Land Resources Assessment. Pub. by: Publisher Oxford University press.

Fardis, M.N., Carvalho, E., Elnashai, A.S., Faccioli, E., Pinto, P., \& Plumier, A. (2005): Designers' Guide to EN 1998-1 and 1998-5, Eurocode 8: Design Provisions for Earthquake Resistant Structures. Pub. by: Thomas Telford Services Limited.

Hengl, T., Heuvelink, G.B. \& Stein, A. (2004): A generic framework for spatial prediction of soil variables based on regression-kriging. Geoderma, 120(1): 75-93.

Idriss I. M. (1999): An update to the Seed-Idriss simplified procedure for evaluating liquefaction potential. Proc., TRB Workshop on New Approaches to Liquefaction, January, 
TECHNOSCIENCE ARTICLE

Publication No. FHWA-RD-99-165, Pub. by: Federal Highway Administration.

Johnson, R.A. \& Wichern, D.W. (1992): Applied multivariate statistical analysis. Pub. by: Prentice hall Englewood Cliffs, NJ.

Joyner, W.B. \& Boore, D.M. (1981): Peak horizontal acceleration and velocity from strong-motion records including records from the 1979 Imperial Valley, California, earthquake. Bull. Seismol.Soc. Am., 71(6): 2011-2038.

Kramer, S.L. (1996): Geotechnical Earthquake Engineering. Pub. by: Pearson Education India.

Oates, J.A. (2008): Lime and limestone: chemistry and technology, production and uses. Pub. by: John Wiley \& Sons.

Seed, H.B., \& Idriss, I.M. (1971): Simplified procedure for evaluating soil liquefaction potential. J. Geotech. Engrg. Div., ASCE, 97(9):1249-1273.

Seed, H., Woodward, Jr. R. \& Lundgren, R. (1962): Prediction of swelling potential for compacted clays. J. Soil Mechan. Found. Div., 88(3):53-88.
Ambient Science, 2018: Vol. 05(1); 22-27 DOI:10.21276/ambi.2018.05.1.ta02

Sorochan, E. \& Ryabova, M. (1988): Pressure of swelling soil against retaining walis. L. Soil Mechan. Found. Div.,25(3): 101105.

Sridharan, A. \& Gurtug, Y. (2004): Swelling behavior of compacted fine-grained soils. Eng. Geol., 72(1): 9-18.

Williams, A.A. \& Donaldson, G.W. (1980): Building on expansive soils in South Africa: 1973-1980. Pub. by: American Society of Civil Engineers.

Youd, T.L., Idriss, I.M. (2001): Liquefaction Resistance of Soils: Summary Report from the 1996 NCEER and 1998 NCEER/NSF Workshops on Evaluation of Liquefaction Resistance of Soils./ J. Geotech. Geoenviron. Eng. 297-313.

Youd, T. L. \& Hoose, S. (1977): Liquefaction susceptibility and geologic setting. Proc., 6th World Conf. on Earthquake Engineering, Indian Society of Earthquake Technology Roorkee, India. 